\title{
The Early Use of Yellow Fever Virus Strain 17D for Vaccine Production in Brazil - A Review
}

\author{
Paulo Roberto Post $/{ }^{*+}$, Ricardo de Carvalho**, Marcos da Silva Freire**, \\ Ricardo Galler*/**
}

\begin{abstract}
Departamento de Microbiologia e Parasitologia, Instituto de Biologia, Universidade Federal de Pelotas, Campus Universitário, Caixa Postal 354, 96010-900 Pelotas, RS, Brasil *Departamento de Bioquímica e Biologia Molecular, Instituto Oswaldo Cruz-Fiocruz, Rio de Janeiro, RJ, Brasil **Instituto de Tecnologia em Imunobiológicos-Fiocruz, Rio de Janeiro, RJ, Brasil
\end{abstract}

The use of yellow fever (YF) virus $17 D$ strain for vaccine production adapted in Brazil since its introduction in 1937 was reviewed. This was possible due to the availability of official records of vaccine production. The retrieved data highlight the simultaneous use of several serially passaged 17D substrain viruses for both inocula and vaccine preparation that allowed uninterrupted production. Substitution of these substrain viruses became possible with the experience gained during quality control and human vaccination. Post-vaccinal complications in humans and the failure of some viruses in quality control tests (neurovirulence for monkeys) indicated that variables needed to be reduced during vaccine production, leading to the development of the seed lot system. The 17DD substrain, still used today, was the most frequently used substrain and the most reliable in terms of safety and efficacy. For this reason, it is possible to derive an infectious cDNA clone of this substrain combined with production in cell culture that could be used to direct the expression of heterologous antigens and lead to the development of new live vaccines.

Key words: yellow fever - vaccine - 17DD strain - virus lineage - immunization

\section{YELLOW FEVER CONTROL IN BRAZIL: EARLY HISTORY}

Mosquito control measures were adopted at the begining of the 20th century to reduce the spread of yellow fever (YF) in several Brazilian cities and their harbors. Two officials were of fundamental importance in this endeavour: Emílio Ribas in the State of São Paulo reaching Sorocaba in 1901, São Simão in 1902 and Ribeirão Preto in 1903; and Oswaldo Cruz in Rio de Janeiro, where he worked until 1908 and freed the city of YF for the following 20 years (Soper 1939, Franco 1969a). With the success of the campaigns in the urban centers, the programme was extended to the interior until few endemic areas were left. The exception was some northeastern areas such as the coasts of States.

\footnotetext{
This work was supported by grants from CNPq, Fiocruz (Papes) and the World Health Organization UNDP/WHO Global Programme for Vaccines.

${ }^{+}$Corresponding author. Fax +55-53-275.7169. E-mail: prpost@ufpel.tche.br

Received 21 October 2000

Accepted 17 April 2001
}

Despite joint work with the Rockefeller Foundation and mosquito control measures, a new outbreak of YF occurred in Rio de Janeiro in 1928, forcing the Brazilian authorities to start a new campaign with 10,000 men led by Dr Clementino Fraga (Soper 1939). Although Emílio Ribas in 1922 and Adolfo Lutz in 1929 (Soper et al. 1933, Franco 1969 b) suspected that other mosquito vectors besides Aedes aegypti could be involved in YF transmission, this issue was only examined in 1932 on the occasion of the Valle do Chanaan outbreak (Soper et al. 1933). In 1936 it was concluded that there were two types of YF transmission, urban and sylvatic, that explained, at least in part, the difficulties in controlling YF in cities (Soper 1936). The presence of other mosquitoes in YF transmission in Brazil was only later confirmed (Shannon et al. 1938).

A process of centralization of YF control by the federal authorities started in 1929. Cheaper methods for mosquito control, the development of a satisfactory procedure for human immunization and the large scale production of human vaccines beginning in 1937, all of which led to the effective control of YF in Brazil (Franco 1969c).

In 1935 the YF Asibi strain (Stokes et al. 1928) was cultivated until passage 58 in whole chicken embryonic tissue and thereafter, until passage 114, 
in denervated chicken embryonic tissue only (Lloyd et al. 1936). At this stage Theiler and Smith (1937a) showed the marked reduction in viral viscero and neurotropism when inoculated intracerebrally in monkeys. This virus was further subcultured until passages 227 and 229 and used without human immune serum to immunize 8 human volunteers (Theiler \& Smith 1937b). The satisfactory results, as shown by the absence of adverse reactions and seroconversion for YF in two weeks, resulted in larger scale immunization being carried out in Brazil (Soper 1937, Smith et al. 1938).

\section{THE USE OF YELLOW FEVER VIRUS 17D STRAIN IN BRAZIL}

In January 1937 Hugh Smith brought the 17D strain to Brazil and the first vaccines were tested in laboratory workers in February (7 people). In the following March, an additional 33 people were vaccinated and the first batches of vaccine to which normal human serum was added were produced (Smith et al. 1938). It should be noted that there was a book of records exclusively for inocula specifications and separate books for recording vaccine production, where the inoculum for each batch is quoted. The following data was retrieved from both types of record book. The first batches of vaccines identified in the records of YF vaccine production in Brazil (numbered 47 to 57) were inoculated on 19 March and 3 August 1937 with subcultures 236, 237 and 238 of the 17DD strain. In June of that year, larger groups (289 people) were vaccinated in the rural areas of the State of Minas Gerais, a campaign that was continued until the end of 1937 by which point 38,266 had been vaccinated (Smith et al. 1938). Until the end of 1940 all vaccine produced in Brazil using the YF virus 17D strain contained normal human serum (numbering of these vaccine lots always started with SF). Due to the observation of icterogenesis in some vaccinees, the vaccine formulation was changed and the addition of normal human serum was discontinued. Other changes in production procedures included the use of pure chicken embryo homogenates as the vaccine preparation (represented by all lots starting with $\mathrm{E}$ or $\mathrm{A}$, the latter meaning embryo supension in water), the preparation of inocula and vaccine batches exclusively in chicken embryos, and later, the development of the seed lot concept.

\section{YF 17D SUBSTRAINS}

Based on the above mentioned record books, the figures and histories that follow summarize the passage of 17D substrains used to generate inocula and vaccine batches in Brazil.

17D-Rio - This substrain probably represents the very first 17D virus passaged in Brazil. It was registered that ampules from the original 17D passages were brought in such as 114,114 plus one passage in mouse brain, 119,150 and 150 plus one passage in mouse brain, but it is not known which substrain was used for vaccination of laboratory personnel upon arrival. At this time, inocula were prepared by continuous passage of the virus in chicken embryo tissue without neural tissue. Normal human serum was added to the supernatants of these cultures and this was used to inoculate embryonated chicken eggs for vaccine production. Official records indicate that the first passage, dated 3 February 1937, was of subculture 155 of the original 17D strain. Since passages were made every 34 days, this would suggest that subculture 150 was initially passaged from January 20 onwards. This was continued until subculture 243 on 8 December 1937 and from these subcultures resulted at least $293 \mathrm{ml}$ of viral inoculum (Table I). These passages also gave rise to substrains 17Dlow-Rio, 17D2-Rio and 17D3-Rio (Fig. 1) which were used for human vaccination in Brazil (Table I). Substrains 17D2-Rio and 17D3-Rio were classified by H A Penna in his diary as directly derived from this 17D-Rio and not from the original USpassaged 17D strain as published by Fox and Penna (1943).

17Dlow-Rio - Fox and Penna (1943) designated the virus derived from subcultures 220 to 243 as 17Dlow-Rio (Fig. 1). This virus was used as inocula for YF vaccine production during the months of September 1937 through to December 1937 (Table I). Although there are records of these passages, it is unclear if this lineage was used with 17DDlow in the vaccination campaigns of September 1937 (Fig. 3). Due to signs of encephalitis observed in two monkeys inoculated intra cerebrally (IC) with vaccine batches, its use was discontinued in 1938 (Table I).

17D2-Rio - According to Penna's diary and Fox and Penna (1943), this substrain was derived from subculture (sc) 200 of the 17D-Rio substrain and was passaged until sc 220 (Fig. 1). It was noted that higher passage levels of the 17D-Rio represented by 17D2-Rio virus correlated with a decrease in virus titer after inoculation of mice (test used for vaccine titration). Therefore, subcultures of the 17D-Rio substrain with lower pasage numbers were used for vaccine production, and designated 17D3-Rio (Fig. 1).

17D3-Rio - This substrain appeared on 1 th August 1939 after cultivation of 17D-Rio at passage 190, and encompasses subcultures 190 through 222 (Fig. 1). Subculture 191 was used for the inoculation of embryonated eggs on $16 \mathrm{Au}$ gust 1939. This vaccine lot (SF542) was inoculated IC into 5 Rhesus monkeys. All animals sur- 


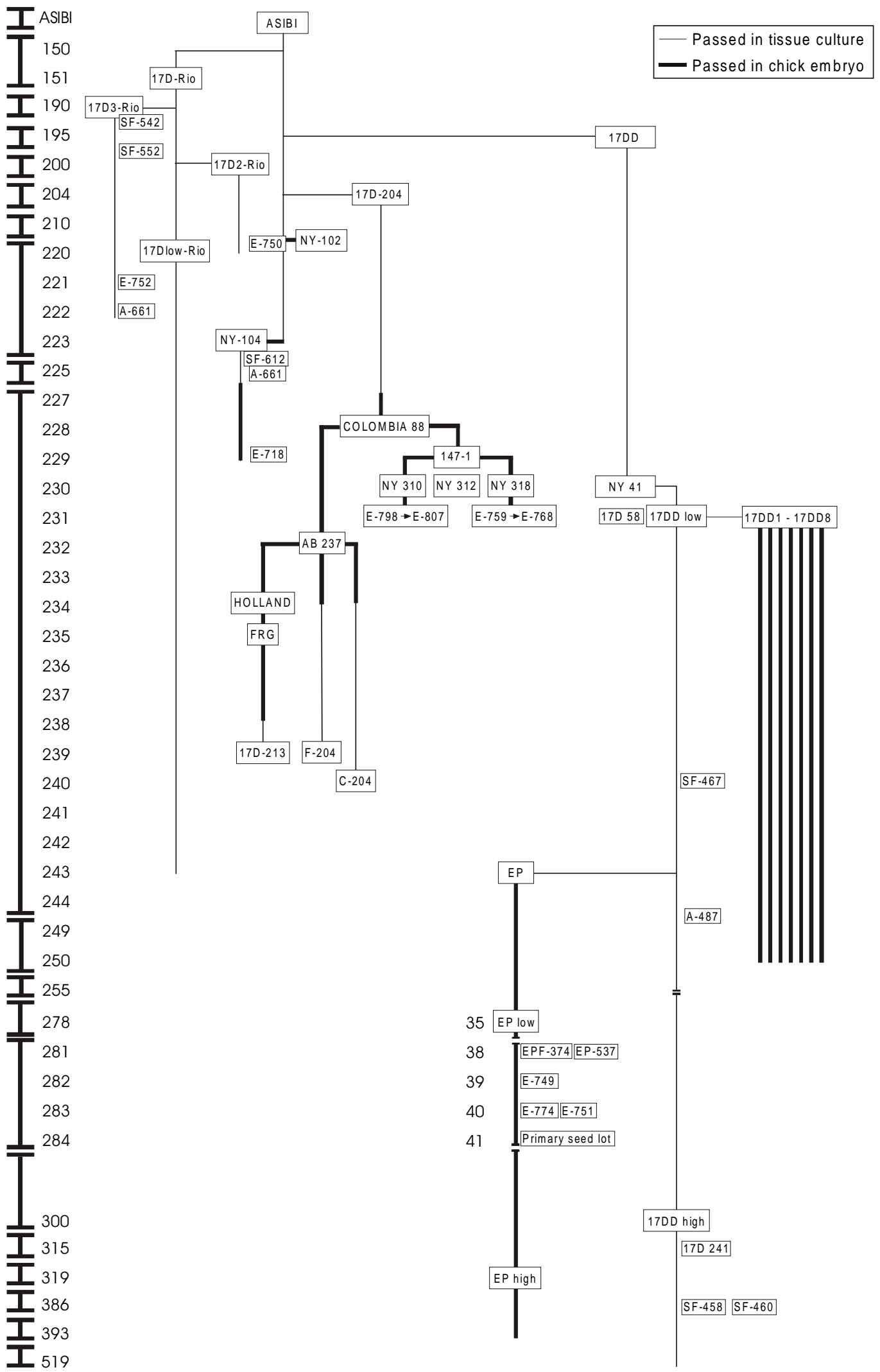

Fig. 1: passage history of yellow fever 17D substrains in Brazil 
TABLE I

Yellow fever 17D substrains used for vaccine production during 1937-1942 in Brazil

\begin{tabular}{|c|c|c|c|c|c|c|}
\hline Substrains & Subculture & Start & End & $\begin{array}{l}\text { Inocula } \\
(\mathrm{ml})\end{array}$ & $\begin{array}{l}\text { Vaccine } \\
(\mathrm{ml})\end{array}$ & $\begin{array}{l}\text { Reason for } \\
\text { discontinued use }\end{array}$ \\
\hline 17D-Rio & $151-219$ & 20 January 1937 & 15 September 1937 & 293 & NA & Icterus (serum) \\
\hline 17Dlow-Rio & $220-243$ & 18 September 1937 & 8 December 1937 & 132 & NA & $\begin{array}{l}\text { Encephalitis in } \\
\text { monkeys }\end{array}$ \\
\hline 17D2-Rio & $200-220$ & 1938 & 1938 & NA & NA & NA \\
\hline 17D3-Rio & $190-222$ & 16 August 1939 & 2 February 1940 & NA & 4,080 & NA \\
\hline 17D NY102 & $213-249$ & 8 March 1940 & 29 August 1940 & 1,317 & 2,668 & NA \\
\hline 17D NY104 & $224-228$ & 5 March 1940 & 29 July 1941 & Vaccine $^{a}$ & 14,073 & $\begin{array}{l}\text { Encephalitis in } \\
\text { monkeys+humans }\end{array}$ \\
\hline 17DNY318 & 231 & 16 December 1941 & 26 February 1942 & Vaccine & 1,820 & Icterus \\
\hline 17DNY310 & 231 & 15 September 1942 & 24 November 1942 & Vaccine & 4,457 & Icterus \\
\hline 17DDhigh & $300-519$ & 11 May 1938 & 28 December 1939 & 969 & 36,125 & $\begin{array}{l}\text { Low } \\
\text { immunogenicity }\end{array}$ \\
\hline 17DDlow & $229-255$ & 19 March 1937 & 21 June 1939 & 365 & 55,778 & Icterus (serum) \\
\hline 17DD1-8 & $230-255$ & 23 June 1939 & 30 May 1940 & Vaccine & 33,842 & NA \\
\hline EPlow & $278-283$ & 22 December 1938 & In use & NA & 13,827 & In use \\
\hline EPhigh & $319-393$ & 24 July 311939 & 8 September 1939 & NA & 2,190 & NA \\
\hline
\end{tabular}

NA: not available; $a$ : vaccine means that the inocula for the subsequent vaccine production was also a lot of vaccine; the amount of inocula in these cases are not available.

vived, but developed an early febrile response by the 2 nd and 3rd days post inoculation. The use of this substrain was approved but only four people had been immunized until February 1940 (SF 552 at sc 196). Fox et al. (1942) used this substrain represented by batch E752 (Fig. 1) to vaccinate 3,561 people of which 2,402 were followed up, suggesting that $0.79 \%$ had symptoms of post-vaccinal encephalitis.

$17 D D$ - This strain was brought in as vaccine NY41 which corresponded to sc 230 of the 17DD substrain (Fig. 1). This substrain was further used for the preparation of inocula by cultivation in chicken embryonic tissue without neural tissue until sc 519 on 28 December 1939. Although the first vaccine recorded as 17DD was produced on 6 August 1937 (lot 17D58) and had NY41as inoculum, all the vaccine batches produced until 21 June 1939 were in fact the 17DD substrain at different passage levels.

17DDhigh - This designation of 17DDhigh was given to passages above sc 300, on 11 May 1938 (Fig. 1). Although the highest 17DD passage level was sc 519, passages used for vaccine production only went up to sc 386 . The first vaccine batch was named 17D 241 (numbered according to vaccine production and not passage level) and was prepared on 19 July 1938 with sc 315 . Batch SF460 was prepared on 12 April 1939 with sc 385 and was the last. There was a significant production of inocula and vaccine (Table I). This substrain was replaced by 17DDlow because it no longer induced immunity in over $20 \%$ of the vaccinees (Soper 1942).

17DDlow - This substrain corresponds to sc 230 through 255 and was used for vaccine production during the period of March 1937 (sc 238) through June 1939 (sc 248). Several vaccine batches caused icterus in vaccinees but this was assumed to be due to contaminated human serum, that was still being added to the vaccine preparations. Nevertheless, the last vaccine batch (SF 508) was produced with the 17DDlow substrain (sc 255) on 21 June 1939. Although less inocula was prepared, more vaccine was produced from it than from 17DDhigh (Table I). There is no information on the use of this vaccine for human vaccination.

17DD1 - 17DD8 - Based on the experience with 17DDlow and high, the original NY41 substrain was reinstated but at this time a series of cultures named 17DD1 to 17DD8 was developed. Each of these cultures was discontinued when its passage level reached sc 250, when another series was started at sc 230. The use of these 17DD passages is depicted in Table I. These vaccine preparations represented a significant part of production from June 1939 to May 1940 (Table I) however there are no records of their use for human vaccination or animal inoculation.

$E P$ - The observations by Penna (data obtained from his diary) that egg passages at that time tended to yield higher virus titers led to new cultivations of the 17DD substrain. One of them started with a low passage virus, namely at sc 243 (Fig. 1), and 
was passed serially in embryonated eggs through passage 150. This new series was started on 18 July 1938 and designated EP (stands for egg passage) being later divided into EPlow (between passages 35 to 40) and EPhigh (75 to 150). This was actually the first virus to be maintained exclusively in embryonated eggs, a procedure which was later expanded to other substrains.

EPlow - The EPlow series encompassed the egg passages 35 through 40 . The subculture EP35 gave rise to the first batch of vaccines of the EPlow series on 22 December 1938. The vaccine batches were always tested for monkey neurovirulence and this EP series was of particular interest, since it was solely passaged in embryonated eggs and its phenotypic characterization in the neurovirulence tests was appealing. On 13 January 1939, five rhesus monkeys were inoculated with EPF374 (EP38) produced 11 days previously. Three monkeys were viremic, but in two animals no virus was detected. By February 13, no monkey showed any sign of nervous system involvement. At this time, 40 doses were used for human immunization. After satisfactory results with the EPF374 vaccine lot, research on the usefulness of the EP series continued and on 12 September 1939, Penna and coworkers vaccinated 48 people in Rio de Janeiro with the EP537 (EP 41) vaccine batch produced a month earlier with the direct inoculum of EP40. Once more, the results were extremely satisfactory and suggested that the safety of this series was even better than that observed for other vaccine batches such as SF-467 (DDlow), SF-458 (DDhigh) and A-487 (DDlow). As shown in Fig. 2, the vaccine batch EPF374 of the EPlow series (EP38) was used to produce batch E749 (EP39) which in turn gave rise to E774 (EP40). E774 corresponds to the 17DDlow strain at egg passage 40 that was used to prepare the primary seed lots as indicated in Fig. 2 , all by further passages in embryonated eggs. In an early clinical trial, Fox et al. (1942) have de- scribed the attenuation of this virus. By using lot E-751 to vaccinate 2,420 people and following up 1,874 , only $0.53 \%$ presented any symptoms related to postvaccinal encephalitis.

EPhigh - Small amounts of vaccine were produced with this series that spanned passages EP 76 to 150 . The main passages used for vaccine production during the period ranging from 24 July to 8 September 1939 were EP 77, EP78, EP 82 and EP 87.

NY102 - In 11 January 1940 the vaccine virus substrain NY102 at sc 212 of the original 17D branch was imported. Its first recorded passage was at sc 213 on 8 March 1940 being further passaged in chicken embryonic tissue without nervous system until sc 249 on 29 August 1940 (Table I). At least 4,452 people were immunized with this virus (vaccine batch E750 at sc 216) and although it was not as encephalitogenic as NY104 it was clearly more so than the EP series in causing clinical symptoms (Fox et al. 1942).

NY104 - The vaccine NY 104 (17D sc 223) arrived in Brazil on 25 January 1940. The first vaccine produced with it was SF-612 (sc 224) in 5 March 1940 and the following were A-661 to A666 (all sc 225) from 3 to 7 June 1940. The passages 226 to 228 were made in embryonated eggs and originated the very first vaccine made up of pure chicken embryo homogenate. This series was also the first to utilize the seed lot system for vaccine production which spanned the period of 11 September 1940 (sc 226) to 29 July 1941 (sc 228). During this period a total of about 2 million YF vaccine doses were produced. On 7 November 1940, it was recorded that from 10 monkeys inoculated with vaccines produced with the NY strain (probably NY104), 4 showed signs of clinical encephalitis, with one death and in May 1941 batch E719 killed a monkey due to encephalitis. Shortly thereafter a physician noted clinical encephalitis in more than 20 vaccinees in the State of Minas

TABLE II

The 17DD1-8 series used for vaccine production

\begin{tabular}{lcllc}
\hline Substrain & Subculture & Start & End & Amount produced \\
\hline DD1 & $230-248$ & 23 June 1939 & 4 August 1939 & $8,182 \mathrm{ml}$ \\
DD2 & $231-246$ & 9 August 1939 & 18 September 1939 & $2,210 \mathrm{ml}$ \\
DD3 & $232-249$ & 29 September 1939 & 13 November 1939 & $4,274 \mathrm{ml}$ \\
DD4 & $230-236$ & 7 November 1939 & 10 May 1940 & $10,406 \mathrm{ml}$ \\
DD5 & $231-236$ & 26 December 1939 & 16 January 1940 & $1,160 \mathrm{ml}$ \\
DD6 & NA & NA & NA & NA \\
DD7 & 231-235 & 19 March 1940 & 30 May 1940 & $2,364 \mathrm{ml}$ \\
DD8 & $231-235$ & 16 May 1940 & & $5,246 \mathrm{ml}$ \\
\hline
\end{tabular}

NA: not available 
Gerais and implicated the vaccination which had been ongoing for two months. Seven vaccine batches were used to vaccinate 55,073 people which corresponded to half the population in that particular area, resulting in clinical manifestations which ranged from mild head ache to severe encephalitis culminating with the death of a vaccinee (Soper 1942) and leading to the discontinued use of this substrain in July 1941. In December 1941, a field trial was carried out in the area of Guaxupé in Minas Gerais in order to select a substrain to continue the production of YF vaccine in Brazil (Fox et al. 1942). Once more, the encephalitic phenotype of substrain NY104 was demonstrated [batch E718, substrain NY310 had been selected, despite the fact it did not compare as favourably with the EP virus also tested in parallel (E751)] (Fox et al. 1942). The substrains tested included 17D3 at sc 221 as E752; NY310/NY-318 plus one passage in embryonated eggs at sc 231, NY104 as the 5th passage in embryonated eggs at sc 228 as E718; NY102 at sc 216 as E-750 and EP40 at sc 283 as E751. Why NY310 was selected is not clear.

NY 310/318 - As depicted in Fig. 1 this substrain represents the 17D-204 lineage. The first vaccines were received in Rio de Janeiro on 21 November 1941 as batches NY310, NY312 and NY318. Between 16 December 1941 and 26 February 1942 the vaccine NY318 (sc 230) was used to produce batches E759 through E768 of pure chicken embryo homogenate. Enough vaccine was produced to vaccinate about 400,000 people. Icterus was observed in 2, 20 and 54 vaccinees of the US Army in 1942 that had been inoculated with substrains NY310, NY312 and NY318 respectively (Sawyer et al. 1944). From 15 September to 24 November 1942, the NY310 substrain was used to produce vaccine batches E798 through E807 yielding enough virus to vaccinate close to a million people. The last batches produced with this substrain on 8 and 9 September 1943 were E828 and E829 derived from the $\mathrm{E} 800$ vaccine.

\section{DISCUSSION}

The main purpose of this paper was to review and summarize the YF virus 17D substrains used for vaccine production in Brazil from 1937 to 1942. We took advantage of the availability of official records for both preparation of viral inocula and vaccine production. These records explain why the 17DD substrain is still being used today for vaccine production in this country.

As shown in Table I and schematically in Fig. 3 , particular substrains overlap according to the time of their use for inocula and/or vaccine production. The substitution of substrain viruses benefited from the experience gained during vaccine production, and quality control by intracerebral inoculation of monkeys and human vaccination. During this process, the appearance of symptomatology led to the discontinuation of a given strain. It should also be noted that more than one strain was used at a given time, and that substrain might have been passaged for the preparation of inocula or vaccine preparation, or both. Not all viruses prepared for inocula were actually used for vaccine production. Details on the production of each batch of vaccines, including the substrain and dates used were retrieved, but are too lenghty to present here.

The concept of the seed lot system

It is obvious that during this period (1937-1942) scientists working on YF vaccine production were not aware of the possibility of phenotypic selection of viruses by serial passage in tissue culture. As production with serially passaged viruses and the vaccination campaigns went on, complications with vaccinees were noted. It was realized that the viral substrains were not as stable from the phenotypic standpoint. We noticed that for all substrains, more inocula was prepared than was actually used for vaccine production and therefore vials of specific passages were usually available. This operating procedure, together with the use of multiple strains at one time, did allow uninterrupted production. With the observation of post-vaccinal complications in humans and also the failure of some viruses in the quality control tests (neurovirulence for monkeys) it became imperative to reduce the variables encountered during vaccine production. One possible solution was to reduce the number of viral passages used for production. This was accomplished by establishing the seed lot system, in which the virus was kept at defined passage levels. Vaccine batches were then produced from that particular passage, which was previously quality tested. In the records we note that the primary impetus for this development was the observation that high passages of DD substrain (named DDhigh) lost immunogenicity in human vaccinees leading to deficient coverage of the local population (Soper et al. 1942, Fox et al. 1943). This observation led scientists back to the initial passages of the DD substrain, more precisely at sc $230 / 231$, which was then used to prepare 8 consecutive inocula (named DD1 to 8). Each of these DD substrains was cultivated for not more than 30 passages. Every passage was actually used for vaccine production but to varying extents.

At this stage, the NY104 substrain was introduced for vaccine production and was the first strain to be fully employed in the seed lot system. It is illustrative to examine Table III, where the effect of such an operating practice can be seen: only three 


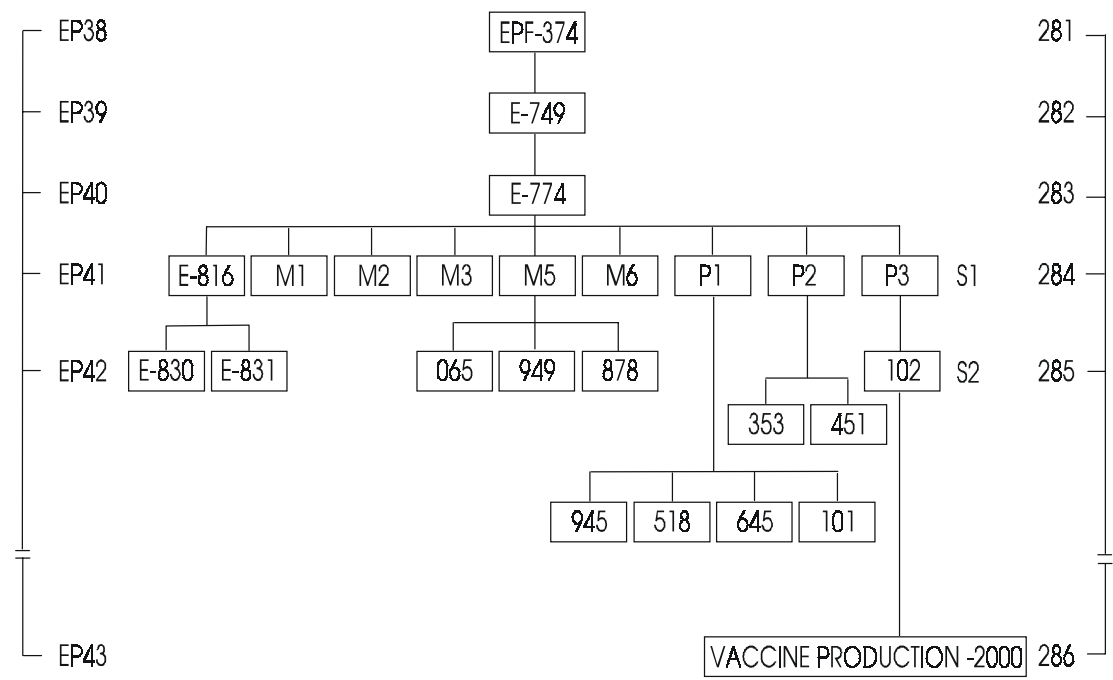

Fig. 2: derivation of primary (S1) and secondary (S2) seed lots from 17DDlow(EP35). The diagram shows the different passages done with the egg passage (EP) series to prepare the primary and secondary seed lots (S1; S2) of the yellow fever 17DD vaccine currently used in Brazil. At the left and right borders are depicted the passage levels of the EP series and Asibi strain, respectively.

seed lots (E688, E694 and E716) were used to produce almost 2 million doses of vaccine during a 10month time interval. Unfortunately, some of these vaccine batches turned out to be encephalitogenic (Fox et al. 1942, Fox \& Penna 1943) and the use of this substrain was discontinued.

The next substrain used was Eplow at sc 243 to produce inocula in embryonated eggs instead of chicken embryonic tissue without neural tissue. There were 150 serial passages of EPlow in embryonated eggs but only 7 of these passages were used for vaccine production. Virus produced in this way performed well in monkey neurovirulence tests and in human vaccination. Therefore, EPlow at chicken embryo passage 37 was used to prepare the EPF374 vaccine which later gave rise to the DD primary and secondary seed lots in use nowadays as depicted in Fig. 2.
The 17DD substrain

As evident from Fig. 3 and Table I, the 17DD substrain was by far the most widely used substrain for both inocula and vaccine production including the EPlow substrain which is still being used nowadays. The complete nucleotide sequence of the genome of 17DD EPlow substrain has been derived (Santos et al. 1995) and its comparison with the sequences available for other substrains like 17D-204 (Rice et al. 1985, Despres et al. 1987) and 17D-213 (Santos et al. 1995) provides an estimate of the extent of genetic variability among these strains. The average number of fixed nucleotide or amino acid sequence changes per passage of the virus is significantly lower for DD suggesting that the 17DD strain is genetically more stable than the others (Galler et al. 1998). This may be important for YF vaccine production.

TABLE III

The use of 17D NY104. Substrains for yellow fever vaccine production

\begin{tabular}{lcll}
\hline SC & From SC & Batches & Date \\
\hline 226 & 225 & E-688 & $9 / 09 / 1940$ \\
227 & E-688 & E-689 - E-697 & $18 / 09 / 1940-22 / 10 / 1940$ \\
& & E-716 & $11 / 03 / 1941$ \\
228 & \multirow{2}{*}{ E-694 } & E-725 - E-726 & $10 / 04 / 1945-15 / 04 / 1945$ \\
& & E-698 - E-713 & $24 / 10 / 1940-19 / 02 / 1941$ \\
228 & E-716 & E-717 - E-721 & $13 / 03 / 1941-27 / 04 / 1941$ \\
& & E-727 - E-728 & $17 / 04 / 1941-23 / 04 / 1941$ \\
& & E-730 - E-741 & $07 / 05 / 1941-29 / 07 / 1941$ \\
\hline
\end{tabular}

$a$ : batches 703, 706, 714, 715, 722, 723, 724, 729, 731, 738 and 739 are not recorded. 


\begin{tabular}{|c|c|c|c|c|c|c|c|c|c|c|c|c|c|c|c|c|c|c|c|}
\hline \multirow{2}{*}{$\begin{array}{l}\text { PERIOD } \\
\text { VIRUS }\end{array}$} & 1937 & \multicolumn{3}{|c|}{1938} & \multicolumn{3}{|c|}{1939} & \multicolumn{4}{|c|}{1940} & \multicolumn{4}{|c|}{1941} & \multicolumn{4}{|c|}{1942} \\
\hline & $\begin{array}{llll}1 & 2 & 3 & 4\end{array}$ & & 2 & 34 & 12 & , & 4 & & 2 & 3 & 4 & & 2 & 3 & 4 & & 2 & 3 & 4 \\
\hline \multicolumn{20}{|l|}{ 17DRio } \\
\hline \multicolumn{20}{|l|}{ 17DlowRlo } \\
\hline \multicolumn{20}{|l|}{ 17D2Rio } \\
\hline \multicolumn{20}{|l|}{ 17D3Rio } \\
\hline \multicolumn{20}{|l|}{ 17D NY102 } \\
\hline \multicolumn{20}{|l|}{$17 D$ NY104 } \\
\hline \multicolumn{20}{|l|}{$17 D$ NY318 } \\
\hline \multicolumn{20}{|l|}{$17 D$ NY310 } \\
\hline \multicolumn{20}{|l|}{ 17DDhigh } \\
\hline \multicolumn{20}{|l|}{ 17DDIow } \\
\hline \multicolumn{20}{|l|}{$170 D 1-8$} \\
\hline \multicolumn{20}{|l|}{ EPlow } \\
\hline EPhigh & & & & & & & & & & & & & & & & & & & \\
\hline
\end{tabular}

Fig. 3: yellow fever substrains used in Brazil from 1937-1942.

\section{Modernization of YF vaccine production}

The phenotypic testing of the virus recovered from the 204 substrain cDNA (Rice et al. 1989, Marchevsky et al. 1995) showed that the virus is suitable for mapping virulence determinants as far as reversion to the wild type phenotype is concerned. However, the slightly higher clinical score observed would preclude its use regarding human vaccine production (Marchevsky et al. 1995). It is also noteworthy that the 204 substrain, used for the preparation of the cDNA library and the infectious cDNA (Rice et al. 1985, 1989), is closely related in terms of lineage and passage number to other 204 substrains (Fig. 1) which brought about clinical symptoms in vaccinees. As 17DD (EPlow) appears to be more genetically stable than the 204 lineage members (Galler et al. 1998) and the DD sequence was determined directly using RNA of virus, for which the phenotype is well established for decades (Santos et al. 1995), it would be of interest to try to derive an infectious cDNA which would be DD-like in its genomic sequence. This DD-like cDNA could become a stable repository for the genome of the YF vaccine virus. Finally, the propagation of RNA virus vaccine strains as DNA with its correspondingly lower mutation frequency combined with efficient production of vaccine virus in cell culture should improve the reliability of YF live attenuated vaccine. In this re- gard, we have recently prepared primary and secondary seed lots with virus derived from such DDlike YF cDNA using primary cultures of chicken embryo fibroblast and the vaccine phenotype of this virus is currently being studied. This cDNA might also be used to direct the expression of heterologous antigens.

Studies on the molecular basis of YF virus virulence/attenuation

Considering the large production of inocula and vaccines using different substrains and the fact that not all the inocula were used up, it would be of interest to know whether any of the strains which caused post vaccinal complications would still be available. Nucleotide sequence analysis of the genome of such viruses might help identify nucleotide/amino acid sequence changes possibly related to the phenotype of a particular substrain and hopefully those related to neurovirulence, since this was the most prominent clinical feature observed in vaccinees (see Table I for strains and clinical features). Nucleotide sequence differences could then have their effects tested by mutagenesis of the YF infectious clone cDNA (preferably DD-like cDNA).

Based on the results described by Fox et al. (1942) it was evident that 17D-NY104 was the most encephalitogenic (particularly lot E-718) and human vaccination with it was discontinued. Vials 
with NY104 at passage 227 were kept in a stock freezer of the Production Unit (as requested by Dr F Soper in 1943) but vaccine lot E-718 at passage 228 was totally discarded in late 1943 , given its proven encephalitic properties. Vials were reconstituted and used to inoculate chicken embryos and Vero cells but have failed to produce detectable virus in plaque formation tests using Vero cells as host. The same procedure was successful for NY 318 (see below) and we are therefore forced to conclude that NY104 does not exist anymore.

We recovered substrain 17D-NY318 from its original vial (Rockefeller Foundation 1941) and propagated it twice in embryonated chicken eggs in order to amplify the virus titer. This virus was produced under GMP, according to current manufacturing methodology and tested for monkey neurovirulence as described (Marchevsky et al. 1995). This testing was necessary because NY 318 was previously implicated in cases of icterus and its use was discontinued. This virus appeared to be attenuated and immunogenic to an extent comparable to our well-known vaccine strain 17DD.

Unfortunately, there are no other substrains kept in the stocks of Fiocruz and therefore the information to be gained on the molecular basis of YF virus neurovirulence/reversion will be very limited given the available samples.

\section{ACKNOWLEDGEMENTS}

To the Yellow Fever Vaccine Production Unit of Fiocruz for their constant support and making available the YF vaccine production records. To Drs AR Nicolau, MJ Cerqueira, JF Cunha for helpful discussions.

\section{REFERENCES}

Despres P, Cahour A, Dupuy A, Deubel V, Bouloy M, Digoutte JP, Girard M 1987. High genetic stability of the coding region for the structural proteins of yellow fever virus strain 17D. J Gen Virol 68: 22452247.

Fox JP, Penna HA 1943. Behavior of 17D yellow fever virus in Rhesus monkeys. Am J Hyg 38: 152-172.

Fox JP, Kossobudzki SL, Cunha JF 1943. Fields sudies on the immune response to $17 \mathrm{D}$ yellow fever virus. Relation to virus substrain dose and route of inoculation. Am J Hyg 38: 113-138.

Fox JP, Lennette EH, Manso C, Souza Aguiar JR 1942. Encephalitis in man following vaccination with 17D yellow fever virus. Am J Hyg 36: 117-142.

Franco O 1969a. Emílio Ribas. In O Franco, História da Febre Amarela no Brasil, Ministério da Saúde, Rio de Janeiro, p. 63-70.

Franco O 1969b. Febre Amarela Silvestre. In O Franco, História da Febre Amarela no Brasil, Ministério da Saúde, Rio de Janeiro, p. 120-127.

Franco O 1969c. Contratos entre o governo brasileiro e a Fundação Rockefeller. In O Franco, História da Febre Amarela no Brasil, Ministério da Saúde, Rio de Janeiro, p. 104-108.
Galler G, Post PR, Santos CND, Ferreira II 1998. Genetic variability among yellow fever virus $17 \mathrm{D}$ substrains. Vaccine 16: 1024-1028.

Lloyd W, Theiler M, Ricci NI 1936. Modification of the virulence of yellow fever virus by cultivation in tissues. Trans $R$ Soc Trop Med Hyg 29: 481-529.

Marchevsky RS, Mariano J, Ferreira VS, Almeida E, Cerqueira MJ, Carvalho R, Pissurno JW, Travassos da Rosa APA, Simões MC, Santos CND, Ferreira II, Muylaert IR, Mann GF, Rice CM, Galler R 1995. Phenotypic analysis of yellow fever virus derived from complementary DNA. Am J Trop Med Hyg 52: 75-80.

Rice CM, Grakoui A, Galler R, Chambers TJ 1989. Transcription of infectious yellow fever RNA from fulllenght templates produced by in vitro ligation. The New Biol 1: 285-296.

Rice CM, Lenches EM, Eddy SR, Shin SJ, Sheets RL, Strauss JH 1985. Nucleotide sequence of yellow fever virus: implications for flaviviruses gene expression and evolution. Science 229: 726-733.

Santos CND, Post PR, Carvalho R, Ferreira II, Rice CM, Galler R 1995. Complete nucleotide sequence of yellow fever virus vaccine strains 17DD and 17D213. Virus Research 35: 35-41.

Sawyer WA, Meyer KF, Eaton MD, Bauer JH, Putnam P, Schwentker FF 1944. Jaundice in army personnel in the western region of the United States and its relation to vaccination against yellow fever (parts II, III and IV). Am J Hyg 40: 35-107.

Shannon RC, Whitman L, Franca M 1938. Yellow fever virus in jungle mosquitoes. Science 88: 110-111.

Smith HH, Penna HA, Paoliello A 1938. Yellow fever vaccination with cultured virus (17D) without immune serum. Am J Trop Med 18: 437-468.

Soper FL 1936. Jungle Yellow Fever. A new epidemiological entity in South America. Rev Hyg Saúde Publ 10: 107-144.

Soper FL 1937. Vaccinação contra a Febre Amarella no Brasil, 1930 a 1937. Arq Hig 7: 379-390.

Soper FL 1939. Progressos realizados nos estudos e combate da Febre Amarela entre a IX e a X Conferências Sanitárias Panamericanas - 1934 a 1938. Arq Hig 9: 65-86.

Soper FL 1942. Febre Amarela Panamericana, 1938 a 1942. Repartição Sanitária Panamericana, Washington, DC, p. 1-12.

Soper FL, Penna HA, Cardoso E, Serafim Jr. J, Frobisher Jr. M, Pinheiro J 1933. Yellow Fever without Aedes aegypti. Study of a rural epidemic in the Valle do Chanaan, Espirito Santo, Brazil, 1932. Am J Hyg 18: 555-587.

Stokes A, Bauer JH, Hudson P 1928. Experimental transmission of yellow fever to laboratory animals. Am J Trop Med 8: 103-164.

Theiler M, Smith HH 1937a. The effect of prolonged cultivation in vitro upon the pathogenicity of yellow fever virus. J Exper Med 65: 767-786.

Theiler M, Smith HH 1937b. The use of yellow fever virus modified by in vitro cultivation for human immunization. J Exper Med 65: 787-800. 
858 Yellow Fever 17D Vaccine - Paulo Roberto Post et al. 